\title{
Ansprache des Leiters der Zivilrechtssektion des Justizministeriums
}

\author{
Sehr geehrte Frau Präsidentin des Obersten Gerichtshofs! \\ Sehr geehrter Herr Präsident der Akademie! \\ Sehr geehrte Damen und Herren!
}

Schon seit einiger Zeit kommen das österreichische Zivilrecht und die österreichische Ziviljustiz gar nicht mehr aus dem Feiern heraus. Das ABGB wird auf den verschiedensten Veranstaltungen gebührend gewürdigt, im Inland wie im Ausland, in Krakau, in Olmütz, in Wien, in Graz, in Salzburg, in Linz, ja auch in Vorarlberg, wo unser ABGB bekanntlich erst später in Kraft getreten ist.

Überall wird, um es mit Franz Klein zu sagen, die Lebenskraft unseres Gesetzbuches gewürdigt, eines Gesetzbuches, das auch nach 200 Jahren unser Zivilrecht immer noch maßgeblich prägt. Außer Streit steht freilich bei allen Veranstaltungen, dass unser gutes altes ABGB eines Relaunches bedarf, um den seit dem Inkrafttreten eingetretenen wirtschaftlichen und gesellschaftlichen Änderungen Rechnung zu tragen. Einer solchen Reform entspricht auch das Regierungsprogramm für die aktuelle, die 24. Gesetzgebungsperiode, wobei sich die Regierungsparteien allerdings darauf verständigt haben, dass solche Änderungen mit Umsicht und mit Augenmaß angegangen werden sollen. Am Charakter und an den Eigenheiten unseres Gesetzbuchs und unseres Zivilrechts soll sich nichts ändern. Das ABGB soll für die nächsten 100 Jahre fit gemacht, aber nicht grundlegend umgestaltet werden. Allenthalben werden auf diesen Feiern auch Beständigkeit und Zeitlosigkeit des ABGB betont, und in der Tat ist es ja so, dass sich zahlreiche Regelungen unseres Gesetzbuches selbst unter radikal geänderten Verhältnissen bewährt haben. Für manche Bereiche des ABGB-

Privatrechts lässt sich das freilich nicht sagen. Nicht alle von ihnen haben den zuweilen stürmischen wirtschaftlichen und gesellschaftlichen Entwicklungen immer standgehalten. Das gilt auch und insbesondere für das Thema Ihrer heutigen Veranstaltung, das Eherecht. Nirgendwo sonst im Privatrecht spiegeln sich die Änderungen im Verhältnis zwischen Staat und Kirche, in den Einstellungen, in den Bedürfnissen der Menschen, auch in den staatspolitischen Strukturen, so deutlich und dramatisch wider wie im Eherecht. Die geschichtliche Entwicklung dieses Bereichs ist außerordentlich bedeutsam, und ich bin mir sicher, dass Ihre Veranstaltung zu diesen Aspekten interessante Einblicke liefern wird. Auch wenn in den letzen Jahrzehnten und Jahren im Eherecht wichtige Modernisierungsschritte gesetzt worden sind, kommt dieser Rechtsbereich den- 
noch nicht zur Ruhe. Er steht, wenn ich so sagen darf, immer noch unter Druck. Kaum, dass es gelungen ist, mit dem Familienrechtsänderungsgesetz 2009 einige wichtige Verbesserungen zu schaffen, kaum, dass die eingetragene Partnerschaft mit ihren Errungenschaften und ihren Problemfeldern in Kraft steht, rücken neue Fragen in den Fokus der rechtspolitischen Diskussion, so etwa zum Stellenwert der Verschuldensscheidung, zur sozialversicherungsrechtlichen und damit auch unterhaltsrechtlichen Absicherung von Ehegatten, zur Frage der Wiedereingliederung des Scheidungsrechts in das ABGB und damit zur endgültigen Überwindung des großdeutschen Ehegesetzes, oder auch zu Fragen der nichtehelichen Lebensgemeinschaft, mit denen sich der kommende Österreichische Juristentag 2012 in Linz befassen wird. Dabei handelt es sich durchwegs um überaus sensible Fragen, die nicht allein rechtlich abgehandelt werden können, sondern in denen es auch und gerade um grundlegende gesellschaftspolitische Einstellungen und Haltungen geht - um das Leitbild von der Ehe, um die Stellung und den Stellenwert der Frau im Privat- und Arbeitsleben, um den Wandel von der Versorgungsehe hin zu einer Wirtschaftsgemeinschaft und so weiter und so fort. Derartige Themen eignen sich nicht so recht für eine grobschlächtige politische Auseinandersetzung; sie müssen vorsichtig angegangen werden mit Blick auf die gesellschaftlichen Realitäten, aber auch mit der notwendigen ideologischen Festigkeit der Diskussionsteilnehmer. Ich bin mir dessen sicher, dass Ihre Tagung für die rechtspolitische Debatte wichtige Impulse liefern kann. Einmal richtet sich der Blick noch auf die Vergangenheit, von der wir für dieses Gebiet so Manches lernen können, dann aber auch auf die künftig dem Gesetzgeber zur Verfügung stehenden Optionen.

In diesem Sinn darf ich Ihnen im Namen und im Auftrag der Frau Bundesministerin alles Gute zu ihrer Tagung wünschen: Interessante Beiträge, spannende Diskussionen und Ergebnisse, die die rechts- und gesellschaftspolitische Debatte befruchten und voranbringen sollen und können.

Wien, 16. Juni 2011

Hon.-Prof. Dr. Georg KATHREIN Sektionschef im Bundesministerium für Justiz 